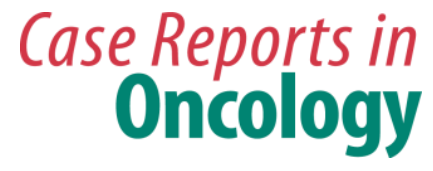

Case Rep Oncol 2017;10:27-36

DOI: $10.1159 / 000455039$

Published online: January 16, 2017

This article is licensed under the Creative Commons Attribution-NonCommercial 4.0

International License (CC BY-NC) (http://www.karger.com/Services/OpenAccessLicense).

Usage and distribution for commercial purposes requires written permission.

\title{
A Case Report of Metastatic Breast Cancer Treated with Korean Medicine Therapy as a Substitute for Chemotherapy
}

\author{
Dong-hyun Lee Sung-su Kim Shin Seong \\ Soram Korean Medicine Hospital, Seoul, Republic of Korea
}

\section{Keywords}

Korean medicine therapy - Breast cancer - Wild ginseng pharmacopuncture - Soramdan S .

Hae $\cdot$ Jeobgoldan

\begin{abstract}
The purpose of this case report is to show the potential benefit of Korean medicine therapy for treating multiple metastatic breast cancer. A 45-year-old Korean woman was diagnosed with right breast invasive ductal carcinoma in August 2012 but did not receive any treatment until October 2015 when she was diagnosed with stage 4 right breast cancer with multiple liver, bone, mesentery, retroperitoneum, and axillary lymph node metastases. After chemoport insertion, she was treated with palliative chemotherapy and the first line of trastuzumab and paclitaxel, and the port was removed due to port infection. To treat sepsis, vancomycin and tazoperan were administered, before the third line of trastuzumab and paclitaxel was carried out. However, the patient gave up chemotherapy due to vancomycin-resistant enterococci and general weakness. Later, she received Korean medicine therapy with wild ginseng pharmacopuncture, distilled Soramdan S, Hae, and Jeobgoldan for 8 months, which led to a significant decrease of the multiple metastases. The patient was able to start walking again
\end{abstract}




\section{Case Reports in Oncology}

with the help of a walking stick. However, a new metastatic lesion was found on the right adrenal gland. This case suggests that the combination of chemotherapy and Korean medicine therapy may be valuable. Further research is indicated.

(C) 2017 The Author(s) Published by S. Karger AG, Basel

\section{Introduction}

Breast cancer is the second most prevalent cancer among women following thyroid cancer. In 2010, 14,277 (14.3\%) out of 99,339 cancer cases found in female patients were breast cancers. The age-adjusted incidence rate of female breast cancer per 100,000 people increased from 24.5 in 1999 to 45.4 in 2010, with a 6\% annual increase [1]. Breast cancer is prone to relapse and metastases: about $40 \%$ of patients who receive radical mastectomy suffer a relapse, with a high probability of developing metastases in the bones, lung, liver, lymph nodes, chest wall, and brain, among others [2].

We report the case of a HER2 3+ breast cancer patient who was diagnosed with liver, mesentery, retroperitoneum, and whole-body bone metastases. After having received chemotherapy with paclitaxel and trastuzumab, the patient decided to suspend chemotherapy due to vancomycin-resistant enterococci (VRE) and general weakness. Subsequently, she received Korean medicine therapy for 8 months, which led to a significant reduction of multiple bone and liver metastases among others.

\section{Case Presentation}

The patient was a 45-year-old South Korean woman who was diagnosed in August 2012 with right invasive ductal carcinoma (T1N0M0) at a Medical Center in Seoul. She was recommended to undergo mastectomy but refused it. After refusing to receive any treatment for the tumor for 3 years, she was eventually hospitalized at a university hospital located in Seoul due to severe back pain, jaundice, and ascites. The PET-CT examination performed on October 19, 2015, showed right breast cancer and metastases in the liver, mesentery, retroperitoneum, both pelvic bones, cranium, whole-body bone, as well as pleural effusion and ascites. Due to the extreme probability of whole-body fractures as a result of multiple bone metastases, the patient was maintained in absolute bed rest. The biopsy results for estrogen receptor, progesterone receptor, and HER2 were,+- , and 3+, respectively. After chemo-port insertion, on October 28, 2015, first-line trastuzumab and paclitaxel treatment was performed by using palliative chemotherapy, followed by ascites and pleural effusion puncture. However, the chemo-port was removed due to port infection. From November 2, 2015, the patient began Korean medicine therapy after she was prescribed oral herbal medicine at Soram Korean Medicine Hospital. On November 20, 2015, second-line therapy was carried out with only trastuzumab, and, from December 13 to December 24, 2015, vancomycin and tazoperan were administered to treat gram-positive and gram-negative sepsis. Abdominal CT and bone scan performed on December 28, 2015, showed a reduction of multiple liver metastases in comparison to the previous result. However, it seemed to be combined with contraction of the liver parenchyma, and ascites and peritoneum metastasis were still visi- 


\section{Case Reports in Oncology}

Case Rep Oncol 2017;10:27-36

DOI: $10.1159 / 000455039$

(C) 2017 The Author(s). Published by S. Karger AG, Basel www.karger.com/cro

Lee et al.: A Case Report of Metastatic Breast Cancer Treated with Korean Medicine Therapy as a Substitute for Chemotherapy

ble. Pleural effusion on both sides increased, and, despite a slight decrease of bone metastases in some areas, new lesions were found on the sternum, left third and fourth ribs, and right acetabulum. After third-line chemotherapy with trastuzumab and paclitaxel on December 30, 2015, the patient was found to have VRE and gave up chemotherapy. Later, from January 22, 2016, to August 8, 2016, the patient received only Korean medicine therapy, which was evaluated based on CT and PET-CT performed at the university hospital where she had previously received chemotherapy. The abdominal CT image on May 30, 2016, showed a noticeable reduction of the liver metastasis lesion as well as scar and contraction of the liver parenchyma. Bone metastasis was still present. When compared to the test carried out on October 19,2015, the PET-CT result on August 8, 2016, showed a significant reduction of the tumor size in the right breast, the primary site of the tumor, as well as of the right axillary lymph node, liver, and bone metastases. However, on the right adrenal gland, a possible new metastatic tumor appeared (Table 1; Fig. 1, Fig. 2, Fig. 3).

The Korean medicine therapy provided to the patient between November 2, 2015, and August 8, 2016, was based on oral administration of wild ginseng pharmacopuncture (WGP), distilled Soramdan S, Hae, and Jeobgoldan. WGP was used every day or every other day, while Soramdan S and Hae were administered every day or 3 times per week. Jeobgoldan was administered twice per day.

\section{Discussion}

Modern medical treatment options for breast cancer include surgery, chemotherapy, and radiotherapy. The patient reported above refused treatment, despite the early diagnosis that would have allowed her to receive the relevant surgery, and, after about 3 years, she was diagnosed with stage 4 breast cancer with multiple whole-body metastases in the lymph nodes, bones, and liver. Chemotherapy using paclitaxel and trastuzumab was carried out until the second line, and, the CT result in December 2015 showed improvement in the liver metastasis. However, the amount of pleural effusion increased, and the patient was still unable to walk due to multiple bone metastases. Also, as a result of repeated infections and fever caused by VRE, the patient's general condition severely deteriorated. After third-line chemotherapy, the patient decided to stop chemotherapy, and, instead, used only Korean medicine therapy. After 8 months of therapy, overall multiple bone metastasis as well as liver and multiple lymph node metastasic lesions were significantly reduced, allowing the patient to walk on her own with the assistance of a walking stick.

For the Korean medicine therapy, intravenous pharmacopuncture and oral herbal medicine were prescribed. For intravenous pharmacopuncture, the Korean medicine doctor injects liquid medicine made with medicinal herbs into the relevant acupuncture spot or vein. Oral herbal medicine is made by using one or more medicinal herbs in either pills or distillate that can be orally administered to the patient.

All of the intravenous pharmacopuncture and oral herbal medicine was prepared in the pharmacy of our hospital. To make WGP, $100 \mathrm{~g}$ cultivated wild ginseng was mixed with distilled water before distilling it for $2 \mathrm{~h}$. Then, the residue was separated, and the distillate was boiled by using the extractive distiller in a white room to obtain $1,000 \mathrm{~mL}$ intravenous pharmacopuncture liquid, which was then filtered twice by using $0.45-$ and $0.2-\mu \mathrm{m}$ filter 


\section{Case Reports in Oncology}

papers. Subsequently, a measured amount of the liquid was placed into a sterilized container and sealed before being sterilized again in a sterilizer. Soramdan $S$ was made by pulverizing wild ginseng and ginseng treated with high temperature and pressure and mixing them at a ratio of 7:3. Then, the powder mixture was mixed with the same amount of honey, which was then prepared as 8-g pills, wrapped in gold foils. To make Hae 50 distilled medicine, milk vetch root and ginger were mixed at a 1:1 ratio and, after mixing with distilled water, distilled for $4 \mathrm{~h}$ by using an extractive distiller. Then, it was diluted in the 5-times saline solution, and placed in a 50 cc glass bottle for oral administration. Jeobgoldan was made of Davallia mariesii Moore, Paeonia obovata Max., Elephas species, Cnidium officinale Makino, Zanthoxylum mantschuricum, Ligusticum acutilobum S. et Z., Chinemys reevesii (Gray), pyrite, Carthamus tinctorius L., Commiphora myrrha Engl., Angelica anomala Lallemant, Prunus humilis Bunge, and Boswellia neglecta M. Moore at a ratio of 15:15:15:15:15:15:15:10:10:2:2:2:2. The result was 2,000-mg round pills which are $2 \mathrm{~mm}$ in diameter and $100 \mathrm{mg}$ per pill, and single dose of which is 20 pills (Table 2).

Recently, the use of WGP and Soramdan S for tumor treatment has been reported in multiple studies. Lee et al. [3] performed Korean medicine therapy by using WGP, PVP (Prunella vulgaris pharmacopuncture), Soramdan, and Hangamdan S for treating lesions of lymph node metastasis remaining after wedge resection on the lung metastasis in a patient with stage 4 breast cancer. As a result, the lymph node metastasis was eliminated and, after 6 months of treatment, the patient did not show a relapse [3]. Soramdan S contains ginsenoside Rg3 and Rh2. It was shown that treatment of cancer cells in vivo and in vitro with Rg3 results in a reduction of proliferation, metastasis, and mortality [4-8]. Ginsenoside Rh2 has been shown to have an antiproliferative effect on human non-small cell lung cancer. Rh2 is able to block cell proliferation, cause G1 phase arrest, enhance the activity of capase-3, and induce apoptosis in non-small cell lung cancer A549 cells $[9,10]$.

The main ingredients of Hae are milk vetch root and ginger. Ye et al. [11] reported that Astragalus membranaceus polysaccharide can inhibit the proliferation of basal-like breast cancer cell line MDA-MB-468 and downregulate the expression of Akt phosphorylation. Elkady et al. [12] reported that Zingiber officinale treatment suppressed the proliferation and colony formation in breast cancer cell lines MCF-7 and MDA-MB-231.

Jeobgoldan is prescribed to treat fracture and bone parenchyma damage. Among its ingredients, extracts of drynariae rhizoma, paeoniae radix alba, and carthamus tinctorius have been reported in several studies to suppress osteoclast differentiation induced by receptor activator for nuclear factor $\kappa B$ ligand (RANKL) at bone marrow-derived macrophages without cytotoxicity in a dose-dependent manner [13-15].

In this case, during the early stage of treatment, third-line chemotherapy was carried out and part of the liver and bone metastases seemed to have been reduced. However, considering that the amount of pleural effusion had increased, with new lesions of bone metastasis, and that the patient was still unable to walk, it was unlikely that the tumor was being effectively treated. After the patient suspended chemotherapy due to VRE infection and general weakness, she received only Korean medicine therapy for 8 months without any chemotherapy or radiotherapy. As a result of the Korean medicine therapy, the multiple bone and liver metastases were significantly reduced, and the patient was able to walk again with the assistance of a walking stick. However, continuous Korean medicine therapy or chemothera- 
py may be necessary as new metastatic lesions were found on the right adrenal gland and could develop into a tumor in the future.

It is not reasonable to draw a decisive conclusion on the effectiveness of Korean medicine therapy for breast cancer based on this case alone. However, in case breast cancer patients refuse chemotherapy voluntarily or cannot receive chemotherapy due to general weakness, this and other similar reports can provide a clue for the active use of WGP, Soramdan S, Hae, and Jeobgoldan for treating multiple metastases including bone and liver metastases of breast cancer in the future. Future reports and clinical research will need to further demonstrate the effectiveness of Korean medicine therapy.

\section{Statement of Ethics}

The authors have no ethical conflicts to disclose.

\section{Disclosure Statement}

The authors have no conflicts of interest to declare.

\section{References}

1 Ministry of Health and Welfare, National Cancer Center: Annual Report of Cancer Statistics in Korea in 2010. The Korea Central Cancer Registry, 2012.

2 Jung KH: Special review: personalized therapy for advanced breast cancer using molecular signatures. Korean J Med 2009;77:26-34.

-3 Lee DH, Seong S, Kim SS, Kim NR, Han JB: Korean medicine therapy as a substitute for chemotherapy for metastatic breast cancer: a case report. Case Rep Oncol 2015;8:64-71.

4 Fishbein AB, Wang CZ, Li XL, et al: Asian ginseng enhances the anti-proliferative effect of 5-fluorouracil on human colorectal cancer: comparison between white and red ginseng. Arch Pharm Res 2009;32:505-513.

5 Wang CZ, Aung HH, Zhang B, et al: Chemopreventive effects of heat-processed Panax quinquefolius root on human breast cancer cells. Anticancer Res 2008;28:2545-2551.

6 Xu TM, Cui MH, Xin Y, et al: Inhibitory effect of ginsenoside Rg3 on ovarian cancer metastasis. Chin Med J (Engl) 2008;121:1394-1397.

7 Lishi H, Tatsuta M, Baba M, et al: Inhibition by ginsenoside Rg3 of bombesin-enhanced peritoneal metastasis of intestinal adenocarcinomas induced by azoxymethane in Wistar rats. Clin Exp Metastasis 1997;15:603-611.

8 Chen J, Peng H, Ou-Yang X, et al: Research on the antitumor effect of ginsenoside Rg3 in B16 melanoma cells. Melanoma Res 2008;18:322-329.

-9 Zhang C, Yu H, Hou J: Effects of 20 (S)-ginsenoside Rh2 and 20 (R)-ginsenoside Rh2 on proliferation and apoptosis of human lung adenocarcinoma A549 cells (in Chinese). Zhongguo Zhong Yao Za Zhi 2011;36:1670-1674.

10 Cheng CC, Yang SM, Huang CY, Chen JC, Chang WM, Hsu SL: Molecular mechanisms of ginsenoside Rh2mediated G1 growth arrest and apoptosis in human lung adenocarcinoma A549 cells. Cancer Chemother Pharmacol 2005;55:531-540.

11 Ye MN, Chen HF, Zhou RJ, Liao MJ: Effects of Astragalus polysaccharide on proliferation and Akt phosphorylation of the basal-like breast cancer cell line (in Chinese). Zhong Xi Yi Jie He Xue Bao 2011;99:1339-1346. 


\section{Case Reports in Oncology}

Lee et al.: A Case Report of Metastatic Breast Cancer Treated with Korean Medicine

Therapy as a Substitute for Chemotherapy

12 Elkady AI, Abuzinadah OA, Baeshen NA, Rahmy TR: Differential control of growth, apoptotic activity, and gene expression in human breast cancer cells by extracts derived from medicinal herbs Zingiber officinale. J Biomed Biotechnol 2012;2012:614356.

13 Kwak SC, Moon SY, Kwack HB, Jeon BH, Min OJ, Choi MK, Kim JJ, Jang SJ: Effect of drynariae rhizoma in RANKL-induced osteoclast differentiation. Korean J Orient Med Physiol Pathol 2012;26:506-510.

14 Park BR, Park GH, Gu DR, Ko WM, Kim YC, Lee SG: Inhibitory effect of paeoniae radix alba ethanol extract on oseoclast differentiation and formation. Korean J Orient Med Physiol Pathol 2015;29:51-57. Ann JY, Kim JH, Ki JY, Kwak HB, Oh JM, Kim YK: Inhibitory effects of water extract of cervi parvum cornu, carthami tinctorii fructus and their combination on osteoclast differentiation and bone resorption. J Korean Orient Med Prescription 2010;18:167-182.

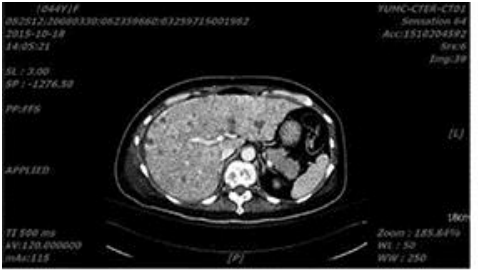

a

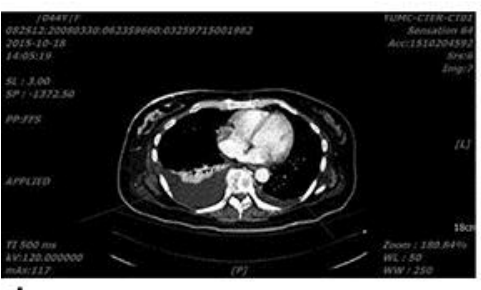

d

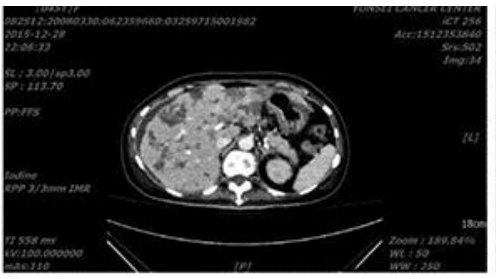

b

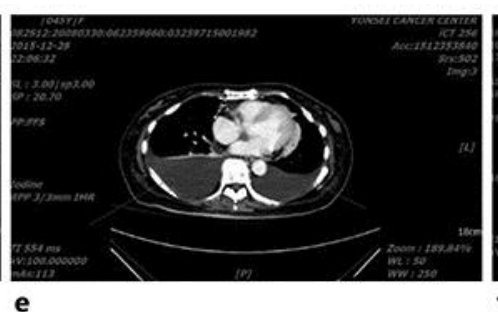

e

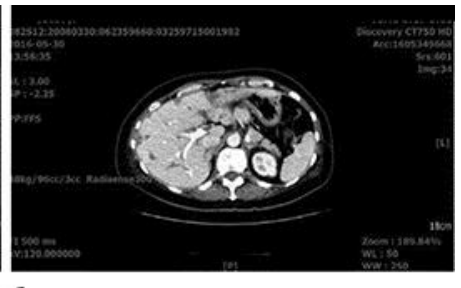

c

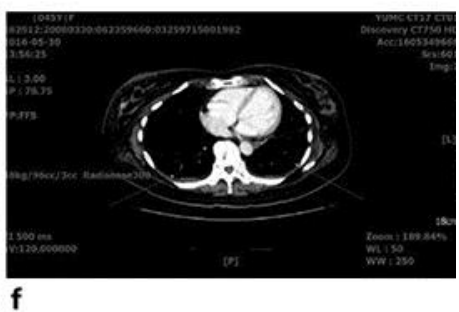

Fig. 1. Radiological images showing the Korean medicine therapy and chemotherapy effects as well as those of Korean medicine therapy alone. a Abdominal CT image showing multiple liver metastases on October 18, 2015. b Abdominal CT image showing multiple liver metastases on December 28, 2015. c Abdominal CT image showing decreased multiple liver metastases on May 30, 2016. d Chest CT image showing pleural effusion on October 18, 2015. e Chest CT image showing increased pleural effusion on December 28, 2015. f Chest CT image showing that pleural effusion almost disappeared on May 30, 2016. 


\section{Case Reports in Oncology}

\begin{tabular}{l|l}
\hline Case Rep Oncol 2017;10:27-36 \\
\hline DOI: 10.1159/000455039 & $\begin{array}{l}\text { (c) 2017 The Author(s). Published by S. Karger AG, Basel } \\
\text { www.karger.com/cro }\end{array}$ \\
\hline
\end{tabular}

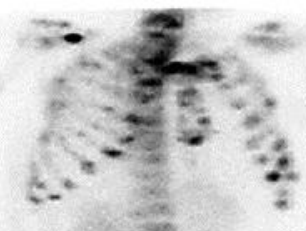

RMO

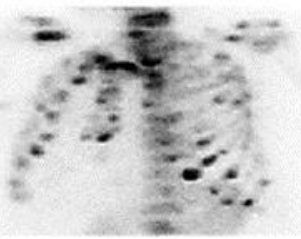

a

L $\Omega$

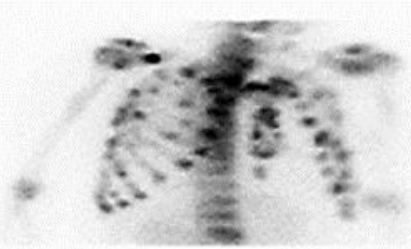

RAO

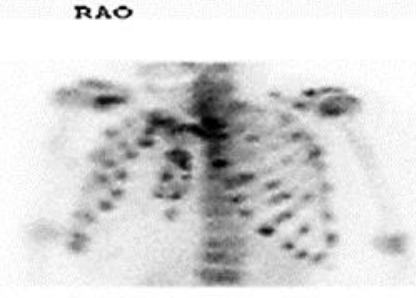

b

L nO

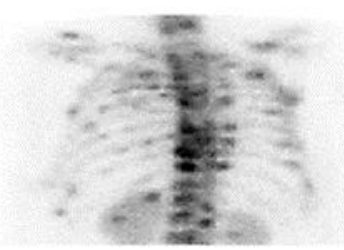

LPO

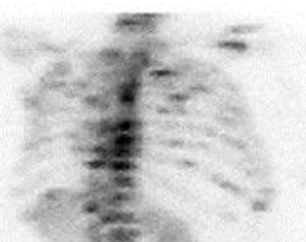

RPO

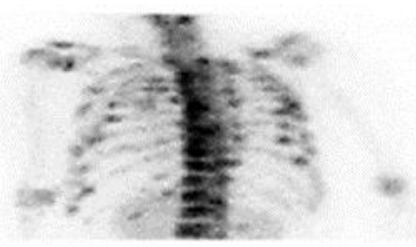

LPO

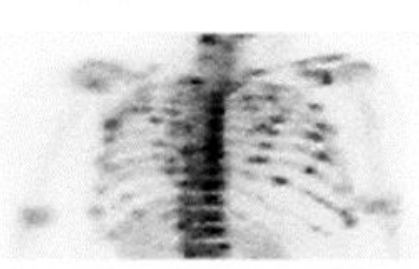

RPO

Fig. 2. Upper-body bone scan images showing the Korean medicine therapy and chemotherapy effects as well as those of Korean medicine therapy alone. a Upper-body bone scan image showing multiple bone metastases on October 20, 2015. b Upper-body bone scan image showing newly increased uptake in the sternal body as well as the left third and fourth ribs on December 28, 2015. 


\section{Case Reports in Oncology}

\begin{tabular}{|c|c|}
\hline DOI: $10.1159 / 000455039$ & $\begin{array}{l}\text { (C) } 2017 \text { The Author(s). Published by S. Karger AG, Basel } \\
\text { www.karger.com/cro }\end{array}$ \\
\hline
\end{tabular}

Lee et al.: A Case Report of Metastatic Breast Cancer Treated with Korean Medicine Therapy as a Substitute for Chemotherapy
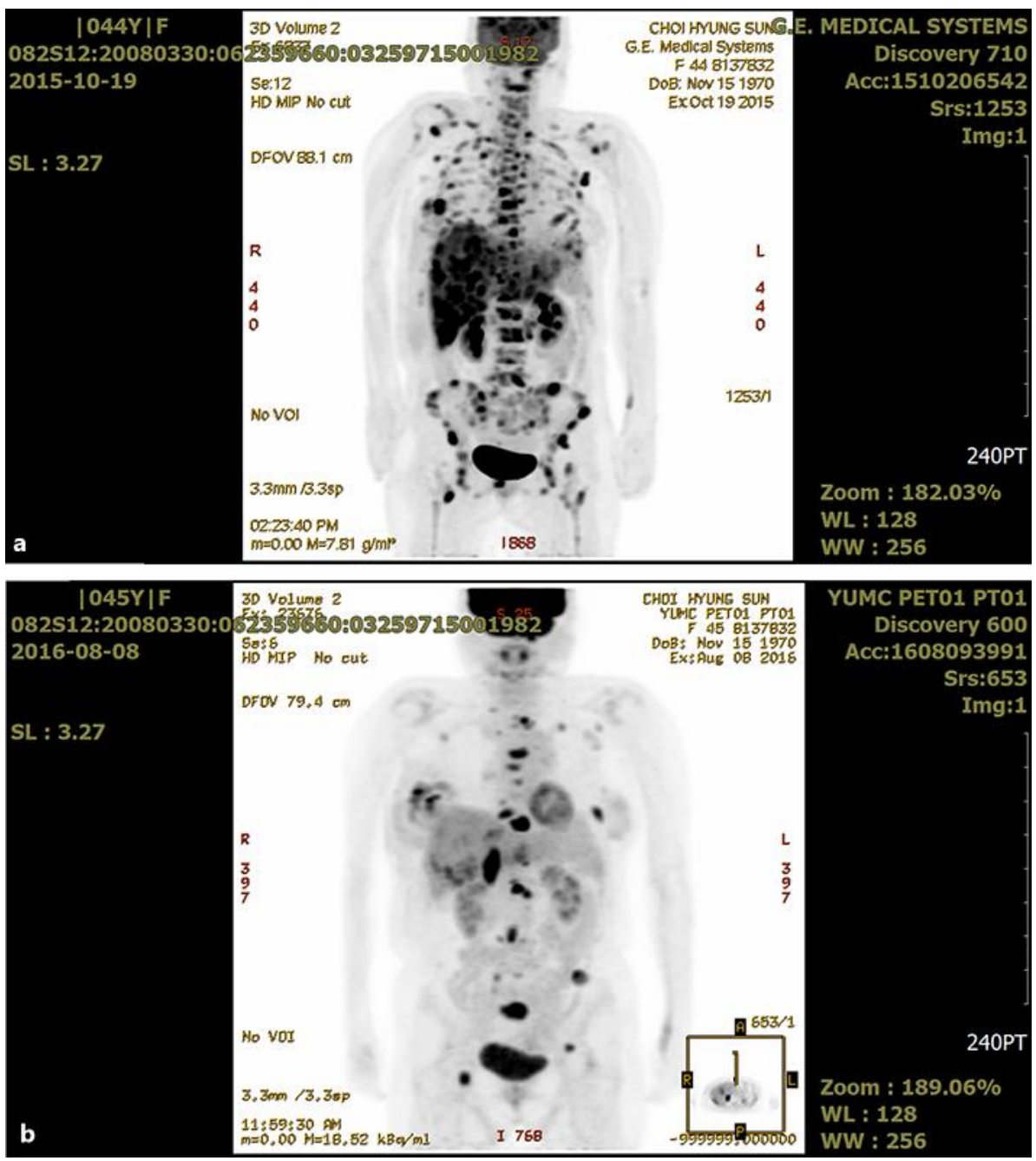

Fig. 3. PET-CT images showing the Korean medicine therapy and chemotherapy effects as well as those of Korean medicine therapy alone. a PET-CT image showing right breast tumor as well as multiple lymph node, liver, and bone metastases on October 19, 2015. b PET-CT image showing markedly decreased multiple lymph node, liver, and bone metastases in August 8, 2016. 


\section{Case Reports in Oncology}

Lee et al.: A Case Report of Metastatic Breast Cancer Treated with Korean Medicine Therapy as a Substitute for Chemotherapy

Table 1. Radiological image reading of Korean medicine therapy and chemotherapy

\begin{tabular}{|c|c|}
\hline $\begin{array}{l}\text { Date and } \\
\text { method of } \\
\text { inspection }\end{array}$ & Image reading \\
\hline $\begin{array}{l}\text { October 18, } 2015 \\
\text { CT }\end{array}$ & $\begin{array}{l}\text { Multiple low-attenuating lesions with rim enhancement are scattered in the liver, probably } \\
\text { metastases } \\
\text { Mild swelling of the pancreatic head with peripancreatic infiltration and moderate ascites, rule out } \\
\text { acute pancreatitis, without parenchymal necrosis } \\
\text { Multiple mesenteric and left gastric LNs are probably reactive ones (differential diagnosis LN } \\
\text { metastasis) } \\
\text { Multiple osteolytic lesions involving the axial skeleton and pelvic bone, probably bone metastases } \\
\text { Bilateral pleural effusion }\end{array}$ \\
\hline $\begin{array}{l}\text { October 19, } 2015 \\
\text { PET-CT }\end{array}$ & $\begin{array}{l}\text { Malignant tumor in the right breast } \\
\text { Metastatic tumors involving both hepatic lobes } \\
\text { Mild pancreatitis } \\
\text { Ascites } \\
\text { LNs with increased FDG uptake in the mesentery, retroperitoneum, bilateral iliac chains are more } \\
\text { likely to be metastatic LNs } \\
\text { Diffuse skeletal metastases } \\
\text { Right pleural effusion }\end{array}$ \\
\hline $\begin{array}{l}\text { October 20, } 2015 \\
\text { Bone scan }\end{array}$ & $\begin{array}{l}\text { Diffusely increased uptakes in the skull, whole axial and proximal appendicular long bones, } \\
\text { suggestive of diffuse bone metastases }\end{array}$ \\
\hline $\begin{array}{l}\text { December 28, } \\
2015 \\
\text { CT } \\
\text { Bone scan }\end{array}$ & $\begin{array}{l}\text { Decreased extent of previous multiple metastases, combined with liver parenchymal contraction } \\
\text { Ascites with irregular peritonitis along the bilateral paracolic gutters and pelvic peritoneum; } \\
\text { suspicion of early carcinomatosis } \\
\text { Increased amount of bilateral plural effusion } \\
\text { Diffuse bone metastasis } \\
\text { Slightly decreased intensity of known metastases in the skull, whole axial and proximal } \\
\text { appendicular long bones } \\
\text { Newly developed increased uptake in the right acetabulum, sternal body, and left third and fourth } \\
\text { ribs }\end{array}$ \\
\hline $\begin{array}{l}\text { May 30, } 2016 \\
\text { CT }\end{array}$ & $\begin{array}{l}\text { Considerably decreased multiple low attenuating lesions in the liver } \\
\text { Scar and contraction of liver parenchyma of the right lobe of the liver } \\
\text { Eccentric thickening of the bowel wall from gall bladder metastasis or chronic cholecystitis } \\
\text { Endurable sclerotic lesions in the spine and pelvic bone suggest bony metastasis }\end{array}$ \\
\hline $\begin{array}{l}\text { August 8, } 2016 \\
\text { PET-CT }\end{array}$ & $\begin{array}{l}\text { Overall, decrease in size of known breast cancer involvement in the right breast, right axillary LNs, } \\
\text { liver, and bone, with viable malignancy } \\
\text { Slight decrease in size of the primary tumor in the right breast } \\
\text { Still intense, mass-like FDG uptake in the bones, predominantly axial skeleton } \\
\text { Decreased but residual irregular uptake in the liver } \\
\text { Newly developed right adrenal mass with increased FDG uptake, suggestive of metastasis }\end{array}$ \\
\hline
\end{tabular}

LN, lymph node; FDG, fluorodeoxyglucose. 


\section{Case Reports in Oncology}

Lee et al.: A Case Report of Metastatic Breast Cancer Treated with Korean Medicine

Therapy as a Substitute for Chemotherapy

Table 2. Prescription of Jeobgoldan

\begin{tabular}{llc}
\hline $\begin{array}{l}\text { Jeobgoldan } \\
\text { Herb }\end{array}$ & Latin botanical name & $\begin{array}{l}\text { Relative } \\
\text { amount, mg }\end{array}$ \\
\hline 骨碎補 & Davallia mariesii Moore & 225.5 \\
白药藥 & Paeonia obovata Max. & 225.5 \\
龍骨 & Elephas Species & 225.5 \\
川芦 & Cnidium officinale Makino & 225.5 \\
川椒 & Zanthoxylum mantschuricum & 225.5 \\
當歸 & Ligusticum acutilobum S. et Z. & 225.5 \\
龜板 & Chinemys reevesii (Gray) & 225.5 \\
自然銅 & Pyrite & 150.4 \\
紅花子 & Carthamus tinctorius L. & 150.4 \\
沒藥 & Commiphora myrrha Engl. & 30.1 \\
白芷 & Angelica anomala Lallemant & 30.1 \\
郁李仁 & Prunus humilis Bunge & 30.1 \\
乳香 & Boswellia neglecta M. Moore & 30.1 \\
\hline Total amount & (1 dose) & $1,999.7$ \\
\hline
\end{tabular}

